\title{
Comparison between clinical features and prognosis of malignancy- and non- malignancy-associated pediatric hemophagocytic lymphohistiocytosis
}

Hua Pan ${ }^{1}$, Yongmin $\mathrm{HuO}^{2}$ and Lirong Sun ${ }^{1 *}$

\begin{abstract}
Background: The differences between the clinical characteristics and survival time in malignancy- and nonmalignancy-associated secondary hemophagocytic lymphohistiocytosis $(H L H)$ are unclear. Here, we describe the clinical characteristics, prognostic factors, and survival outcomes of malignancy-associated HLH compared to that of non-malignancy-associated HLH.

Methods: We retrospectively analyzed 91 pediatric patients with HLH (age < 14 years) at the Affiliated Hospital of Qingdao University Pediatric Department between January 2005 and October 2016. The patients were divided into the malignancy-associated group $(n=22)$ and non-malignancy-associated group $(n=69$, also considered the control group). The clinical features were compared using the Mann-Whitney $U$ and $x^{2}$ tests. The overall survival time was compared using log rank and Mann-Whitney $U$ tests.

Results: Hemoglobin (HGB; $p=0.004$ ), alanine aminotransferase (ALT; $p=0.002)$, and aspartate aminotransferase (AST; $p=0.001$ ) levels in the malignancy-associated group differed from that in the non-malignancy-associated group. The mean survival times were $26.9 \pm 3.82$ months (malignancy-associated HLH) and $35.03 \pm 2.19$ months (non-malignancy-associated HLH). The overall survival time between the two groups was not statistically significantly different $(p=0.055)$. Univariate analysis showed that disseminated intravascular coagulation (DIC) score $>5(p=0.001)$, albumin $<25 \mathrm{~g} / \mathrm{L}(p=0.000), \mathrm{HGB}<60 \mathrm{~g} / \mathrm{L}(p=0.001)$, and platelet count $(\mathrm{PLT})<30 \times 10^{9} / \mathrm{L}$ $(p=0.042)$ correlated with prognosis. Multivariate Cox analysis showed that albumin $<25 \mathrm{~g} / \mathrm{L}(p=0.017), \mathrm{HGB}<60$ $\mathrm{g} / \mathrm{L}(p=0.027)$, and bone marrow hemophagocytosis $(p=0.034)$ correlated with worse prognosis.
\end{abstract}

Conclusions: Patients with non-malignancy-associated HLH do not have better survival, although their prognosis is relatively better in clinical practice. A higher DIC score at diagnosis and lower albumin, HGB, and PLT levels are negative prognostic factors in malignancy-associated $\mathrm{HLH}$.

Keywords: Hemophagocytic lymphohistiocytosis, Hematopoietic stem cell transplantation, Perforin, Child

\footnotetext{
* Correspondence: sunlr@vip.sina.com

${ }^{1}$ Department of Paediatric Hematology, Affiliated Hospital of Qingdao

University, 16 Jiangsu Road, Qingdao 266003, Shandong, China

Full list of author information is available at the end of the article
}

(c) The Author(s). 2019 Open Access This article is distributed under the terms of the Creative Commons Attribution 4.0 International License (http://creativecommons.org/licenses/by/4.0/) which permits unrestricted use, distribution, and reproduction in any medium, provided you give appropriate credit to the original author(s) and the source, provide a link to the Creative Commons license, and indicate if changes were made. The Creative Commons Public Domain Dedication waiver (http://creativecommons.org/publicdomain/zero/1.0/) applies to the data made available in this article, unless otherwise stated. 


\section{Background}

Hemophagocytic lymphohistiocytosis (HLH) is characterized by aberrant activation and proliferation of polyclonal $\mathrm{CD}^{+} \mathrm{T}$ lymphocytes and macrophages that infiltrate multiple organs and overproduce inflammatory cytokines [1]. HLH has been characterized as primary HLH or secondary HLH (SHLH). Primary HLH is often associated with inherited gene defects.

SHLH generally occurs later in life than primary HLH. SHLH is an acquired phenomenon that develops in response to severe infections, autoimmune or rheumatologic disorders, drugs, and in association with concurrent malignancies [2]. Malignancy-associated HLH is most commonly seen in acute leukemia in children. HLH can occur as initial HLH or concomitantly with malignant disease. The mechanism of malignancy-associated hemophagocytosis is not well understood, and may be associated with cytokine secretion (including interferon- $\gamma$ and interleukin-6), persistent antigen stimulation by malignant cells, chemotherapyinduced immunosuppression, hematopoietic stem cell transplantation (HSCT), or infection [3].

The difference between malignancy- and nonmalignancy-associated (i.e., causes other than tumor) HLH remains unclear. We retrospectively reviewed patients with malignancy- and non-malignancy-associated HLH at our institution and compared the clinical characteristics, treatment response, overall survival time, and prognostic factors of the two groups. In this study, we also share our limited experiences with allogeneic HSCT in malignancy-associated HLH. We aimed to distinguish between malignancy-associated and non-malignancy-associated HLH, compare their clinical features and prognostic significance, and analyze the difference between the two conditions.

\section{Methods}

\section{Participants}

The clinical data of 91 patients aged $<14$ years who had been diagnosed with HLH from January 2005 to October 2016 at the Children Medical Center of the Affiliated Hospital of Qingdao University were included and retrospectively reviewed after we had received University of Qingdao Ethics Committee approval. A retrospective historical cohort study was carried out. Primary HLH was excluded.

Patients were diagnosed with HLH according to HLH2004 diagnostic guidelines [4] and were divided into malignancy-associated HLH ( $n=22 ; 13$ boys and nine girls) and non-malignancy-associated HLH $(n=69 ; 30$ boys and 39 girls) groups for improved comparison of the clinical features and outcome. The data collected for each patient included age, sex, presence or absence of splenomegaly, neutrophils (absolute neutrophil count, ANC), hemoglobin (HGB), platelet (PLT), Epstein-Barr virus (EBV) DNA copy number, aspartate aminotransferase (AST), alanine aminotransferase (ALT), lactate dehydrogenase (LDH), albumin, presence of jaundice, presence of cholecystitis, triglycerides (TGs), fibrinogen (Fib), ferritin, disseminated intravascular coagulation (DIC) score, and bone marrow hemophagocytosis. The DIC score at admission was calculated in accordance with International Society of Thrombosis Hemostasis criteria [5].

\section{Statistical analysis}

The clinical features of the two groups were compared using Mann-Whitney $U$ tests for skewed continuous data, and with $x^{2}$ tests for categorical data. All results are presented as the median and range ( $\min -\max )$ as indicated. Overall survival time, defined as the time from HLH diagnosis to death from any cause, was estimated with the Kaplan-Meier method. The overall survival time of the two groups was compared using log rank and Mann-Whitney U tests. The relationship of prognostic factors associated with malignancy-associated HLH was evaluated using Pearson correlation for two normally distributed variables and with Spearman rank correlation for non-normally distributed variables. Prognostic factors associated with malignancy-associated HLH were evaluated using univariate and multivariate Cox proportional hazard models. Multiple group corrections were performed using the false discover rate. In all tests, $p<0.05$ was considered significant. All statistical analyses were performed using SPSS version 13 .

\section{Results \\ Clinical characteristics}

There was no significant difference between age, sex, splenomegaly, ANC, PLT, presence of EBV infection, albumin, presence of jaundice, and presence of cholecystitis in the two groups (Table 1). Serum TG, ferritin, Fib, and LDH levels and presence of DIC were also not significantly different between the two groups. However, patients with nonmalignancy-associated HLH had significantly higher HGB $(p=0.004)$, ALT $(p=0.002)$, and AST $(p=0.001)$ levels than the patients with malignancy-associated HLH.

\section{Malignancy-associated HLH}

The median (range) age of patients in the malignancyassociated HLH group was $3.60(0.25-13.00)$ years. The most frequent histological subtype was leukemia, which was diagnosed in 17 of the 22 patients (77.3\%); the remaining five patients $(22.7 \%)$ had lymphoma [Hodgkin lymphoma (HD), $n=2$; non-HD, $n=3$ )]. Of the 17 children with leukemia, nine had acute lymphoblastic leukemia (ALL; B-ALL, $n=5$; T-ALL, $n=4$ ) and eight had AML.

Thirteen patients $(59.1 \%)$ were treated according to HLH-2004 as initial therapy for HLH, and four patients received chemotherapy as initial therapy. The overall 
Table 1 Clinical features of malignancy-associated hemophagocytic lymphohistiocytosis (M-HLH) and non-malignancy-associated hemophagocytic lymphohistiocytosis (N-M-HLH)

\begin{tabular}{|c|c|c|c|c|c|}
\hline & $\mathrm{M}-\mathrm{HLH}(n=22)$ & N-M-HLH $(n=69)$ & Statistic value & $p$-value & $Q$ value \\
\hline Age [year; median (min, max)] & $3.60(0.25,13.00)$ & $1.20(0.20,13.00)$ & $-2.216^{\dagger}$ & $0.027^{b}$ & 0.135 \\
\hline \multicolumn{6}{|l|}{ Sex } \\
\hline Male & $13.00(59.10 \%)$ & $39.00(56.50 \%)$ & \multirow[t]{2}{*}{$1.111^{*}$} & \multirow[t]{2}{*}{$0.045^{\mathrm{a}}$} & \multirow[t]{2}{*}{0.113} \\
\hline Female & $9.00(40.90 \%)$ & $30.00(43.50 \%)$ & & & \\
\hline \multicolumn{6}{|l|}{ Splenomegaly } \\
\hline No & $3.00(13.60 \%)$ & $22.00(31.90 \%)$ & \multirow[t]{2}{*}{$2.965^{*}$} & \multirow[t]{2}{*}{$0.095^{\mathrm{a}}$} & \multirow[t]{2}{*}{0.211} \\
\hline Yes & 19.00(86.40\%) & $47.00(68.10 \%)$ & & & \\
\hline Neutrophils $\left[10^{9} / \mathrm{L} ;\right.$ median (min, max)] & $1.04(0.05,8.00)$ & $1.10(0.05,10.50)$ & $-0.496^{\dagger}$ & $0.620^{\mathrm{b}}$ & 0.775 \\
\hline Hemoglobin [g/dL; median (min, max)] & $69.50(54.00,115.00)$ & $85.00(31.00,131.00)$ & $-2.879^{\dagger}$ & $0.004^{b}$ & 0.027 \\
\hline Platelets $\left[10^{9} / L ;\right.$ median (min, max)] & $43.50(2.00,293.00)$ & $62.00(7.00,418.00)$ & $-2.077^{\dagger}$ & $0.038^{\mathrm{b}}$ & 0.109 \\
\hline TG [mg/dL; median (min, max)] () & $3.13(0.81,7.55)$ & $3.42(0.05,13.56)$ & $-0.385^{\dagger}$ & $0.700^{\mathrm{b}}$ & 0.778 \\
\hline Fibrinogen [mg/dL median (min, max)] & $1.24(0.58,5.00)$ & $1.20(0.27,4.56)$ & $-0.959^{\dagger}$ & $0.337^{\mathrm{b}}$ & 0.518 \\
\hline Ferritin $[\mathrm{mg} / \mathrm{dL} ;$ median (min, max)] & $1148.50(354.00,21,173.00)$ & $3562.00(132.00,27,810.00)$ & $-0.742^{\dagger}$ & $0.458^{\mathrm{b}}$ & 0.654 \\
\hline LDH [IU/L; median (min, max)] & $1002.50(227.00,17,958.00)$ & $936.00(156.00,5311.00)$ & $-0.649^{\dagger}$ & $0.516^{\mathrm{b}}$ & 0.688 \\
\hline \multicolumn{6}{|l|}{ DIC } \\
\hline No & $18.00(81.80 \%)$ & $44.00(63.80 \%)$ & \multirow[t]{2}{*}{$0.391^{*}$} & \multirow[t]{2}{*}{$0.114^{\mathrm{a}}$} & \multirow[t]{2}{*}{0.228} \\
\hline Yes & $4.00(18.20 \%)$ & $25.00(36.20 \%)$ & & & \\
\hline \multicolumn{6}{|l|}{ Jaundice } \\
\hline No & $14.00(63.60 \%)$ & $40.00(58.00 \%)$ & \multirow[t]{2}{*}{$0.788^{*}$} & \multirow[t]{2}{*}{$0.638^{\mathrm{a}}$} & \multirow[t]{2}{*}{0.751} \\
\hline Yes & $8.00(36.40 \%)$ & $29.00(42.00 \%)$ & & & \\
\hline \multicolumn{6}{|l|}{ Hemophagocytosis } \\
\hline Yes & $16.00(72.70 \%)$ & $37.00(53.60 \%)$ & \multirow[t]{2}{*}{$2.306^{*}$} & \multirow[t]{2}{*}{$0.114^{\mathrm{a}}$} & \multirow[t]{2}{*}{0.207} \\
\hline No & $6.00(27.30 \%)$ & $32.00(46.40 \%)$ & & & \\
\hline \multicolumn{6}{|l|}{ EBV } \\
\hline Positive (EBV DNA > $1.44 \times 10^{3} /$ copies) & $8.00(36.30 \%)$ & $21.00(30.40 \%)$ & \multirow[t]{2}{*}{$1.306^{*}$} & \multirow[t]{2}{*}{$0.037^{\mathrm{a}}$} & \multirow[t]{2}{*}{0.123} \\
\hline Negative (EBV DNA $<1.44 \times 10^{3} /$ copies) & $14.00(63.70 \%)$ & $48.00(69.60 \%)$ & & & \\
\hline ALT [g/L; median (min, max)] & $77.50(17.00,403.00)$ & $210.00(3.00,5679.00)$ & $-3.110^{\dagger}$ & $0.002^{\mathrm{b}}$ & 0.02 \\
\hline AST [g/L; median (min, max)] & $87.50(19.00,320.00)$ & $210.00(12.00,7654.00)$ & $-3.407^{\dagger}$ & $0.001^{b}$ & 0.02 \\
\hline Albumin [g/L; median (min, max)] & $30.00(18.80,37.60)$ & $29.00(17.91,40.30)$ & $-0.269^{\dagger}$ & $0.788^{b}$ & 0.829 \\
\hline \multicolumn{6}{|l|}{ Cholecystitis } \\
\hline Yes & $1.00(4.5 \%)$ & $10.00(14.5 \%)$ & \multirow[t]{2}{*}{$0.281^{*}$} & \multirow[t]{2}{*}{$0.213^{\mathrm{a}}$} & 0.355 \\
\hline No & $21.00(95.5 \%)$ & $59.00(85.5 \%)$ & & & \\
\hline Pneumonia & & & & & \\
\hline Yes & $10.00(45.50 \%)$ & $32.00(46.40 \%)$ & $0.964^{*}$ & $0.940^{\mathrm{a}}$ & 0.940 \\
\hline No & $12.00(54.50 \%)$ & $37.00(53.60 \%)$ & & & \\
\hline Pleural effusion & & & & & \\
\hline Yes & $3.00(13.60 \%)$ & $26.00(37.70 \%)$ & $0.261^{*}$ & $0.035^{\mathrm{a}}$ & 0.140 \\
\hline No & $19.00(86.40 \%)$ & $43.00(62.30 \%)$ & & & \\
\hline
\end{tabular}

TG Triglyceride, LDH Lactate dehydrogenase, DIC Disseminated intravascular coagulation, HLH Hemophagocytic lymphohistiocytosis

$Q$-value: $P$ value after multiple group corrections

${ }^{a} p$-value for $x^{2}$ test; *: Odds Ratio for Chi-square test

${ }^{\mathrm{b}} p$-value for Mann-Whitney U test; + : Z value for Mann-Whitney $U$ test 
response rate was $68.2 \%$ (complete remission rate, 40.9\%; partial remission rate, $27.3 \%)$.

\section{Non-malignancy-associated HLH}

The median (range) age of patients in the nonmalignancy-associated HLH group was 1.20 (0.20-13.00) years. Of the 69 patients in the group, 21 (30.4\%) had EBV-associated HLH, 10 (14.5\%) had cytomegalovirus infection, 10 (14.5\%) had bacterial infections, nine (13.0\%) had immunodeficiency diseases (chronic granulomatous diseases, $n=4$; congenital disorder of fucosylation, $n=3$; common variable immunodeficiencies, $n=2)$, five $(7.2 \%)$ had chronic active EBV (CAEV) infection, five (7.2\%) had autoimmune disease (systemic lupus erythematosus [SLE], $n=4$; Still's disease, $n=1)$, two (2.9\%) had fungal infections, and seven (10.1\%) had other diseases.

Forty-one patients (59.4\%) were treated according to HLH-2004 as initial therapy for HLH, 18 patients (26.1\%) received high-dose immunoglobulin and glucocorticoid chemotherapy, and 10 patients (14.5\%) received glucocorticoids only as initial therapy. The overall response rate was $75.6 \%$ (complete remission rate, $55.1 \%$; partial remission rate, $20.5 \%)$.

\section{Outcome}

The mean survival time in the malignancy-associated HLH and non-malignancy-associated HLH groups was $26.9 \pm 3.82$ and $35.03 \pm 2.19$ months, respectively. The difference in the overall survival time between the two groups was not statistically significant $(p=0.055)$ (Fig. 1).

\section{Prognostic factors}

Correlation analysis of the prognostic factors associated with malignancy-associated HLH showed that Fib and DIC ( $r=$ 0.446, $p=0.037)$, ferritin and PLT $(r=0.516, p=0.014)$, ALT ( $r=0.481, p=0.023)$, albumin and PLT $(r=0.483, p=$ $0.023)$, AST and ALT ( $r=0.687, p=0.001)$, and pleural effusion and pneumonia $(r=0.399, p=0.041)$ were correlated. In prognostic analysis, factors with absolute correlation coefficient values exceeding 0.7 (i.e., $r>0.7$ ) should not be simultaneously entered. Therefore, all prognostic factors could be included for prognostic analysis.

We conducted univariate analysis to assess the association between prognostic factors and survival time in malignancy-associated HLH (Table 2). DIC score $>5$ at diagnosis $(p=0.001)$, albumin $<25 \mathrm{~g} / \mathrm{L}(p=0.000), \mathrm{HGB}<$ $60 \mathrm{~g} / \mathrm{L}(p=0.001)$, and PLT $<30 \times 10^{9} / \mathrm{L}(p=0.042)$ were negative prognostic factors for patients with malignancyassociated HLH. Multivariate analysis showed that albu$\min <25 \mathrm{~g} / \mathrm{L} \quad(p=0.017), \mathrm{HGB}<60 \mathrm{~g} / \mathrm{L} \quad(p=0.027)$, and bone marrow hemophagocytosis $(p=0.034)$ correlated with poor prognosis (Table 3 ). The other factors did not significantly affect survival time in the two groups.

\section{Role of allogeneic HSCT in malignancy-associated HLH} In our cohort, only five patients (three patients with leukemia; two patients with lymphoma) received allogeneic HSCT. Four patients achieved complete remission after allogeneic HSCT. One patient with HD achieved partial remission, but died of HD relapse, complicated by infection.

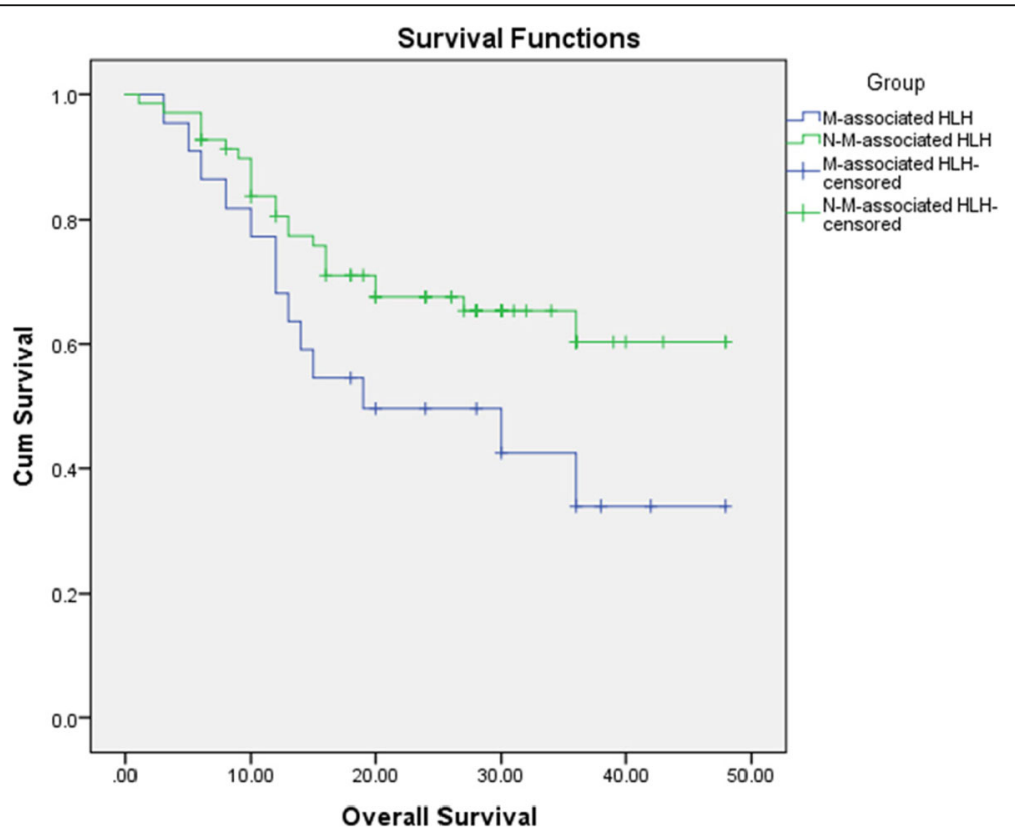

Fig. 1 Kaplan-Meier survival of patients with malignancy-associated HLH and non-malignancy-associated HLH 
Table 2 Results of univariate analysis of prognostic factors of malignancy-associated hemophagocytic lymphohistiocytosis $(\mathrm{HLH})$

\begin{tabular}{lllll}
\hline Variable & HR & $95 \% \mathrm{Cl}$ & $p$ value & $Q$ value \\
\hline Age & 0.966 & $0.873-1.069$ & 0.506 & 0.843 \\
Gender & 0.815 & $0.418-1.587$ & 0.547 & 0.841 \\
EBV-positive & 0.864 & $0.437-1.708$ & 0.674 & 0.963 \\
@Ne & 0.949 & $0.823-1.095$ & 0.476 & 0.865 \\
HGB (<60 g/L) & 0.968 & $0.949-0.987$ & 0.001 & 0.01 \\
Fibrinogen & 1.043 & $0.744-1.462$ & 0.807 & 1.009 \\
Ferritin & 1.000 & $1.000-1.000$ & 0.878 & 1.033 \\
LDH & 1.000 & $1.000-1.000$ & 0.469 & 0.938 \\
DIC & 3.045 & $1.571-5.901$ & 0.001 & 0.007 \\
Jaundice & 1.614 & $0.838-3.109$ & 0.153 & 0.612 \\
Bone marrow involvement & 0.722 & $0.375-1.390$ & 0.330 & 0.733 \\
TG & 0.890 & $0.718-1.103$ & 0.288 & 0.823 \\
PLT (<30 $\left.\times 10^{9} / L\right)$ & 0.993 & $0.985-1.000$ & 0.042 & 0.210 \\
Albumin (<25 g/L) & 0.883 & $0.827-0.943$ & 0.000 & 0.000 \\
ALT & 1.000 & $1.000-1.000$ & 0.951 & 1.001 \\
AST & 1.000 & $1.000-1.000$ & 0.213 & 0.710 \\
Splenomegaly & 1.038 & $0.487-2.210$ & 0.923 & 1.026 \\
Cholecystitis & 1.022 & $0.360-2.896$ & 0.968 & 0.968 \\
Pleural effusion & 0.876 & $0.431-1.781$ & 0.714 & 0.952 \\
Pneumonia & 1.389 & $0.721-2.676$ & 0.325 & 0.813 \\
\hline HR Hazad & & &
\end{tabular}

HR Hazard ratio, EBV Epstein-Barr virus, HGB Hemoglobin, LDH Lactate dehydrogenase, DIC Disseminated intravascular coagulation, TG Triglycerides, PLT Platelets, ALT Alanine aminotransferase, AST Aspartate aminotransferase, $@ N e$ Neutrophils granulocyte

\section{Discussion}

We performed a retrospective analysis of 22 children with malignancy-associated HLH and 69 children with nonmalignancy-associated HLH at a single institution. The pathogenesis of SHLH remains unclear. Delavigne et al. [6] proposed extended 18-point diagnostic criteria that are more easily and rapidly available in smaller institutions and primary care settings than the HLH-2004 variables. Non-malignancy-associated HLH is common in acute self-limited infectious mononucleosis (IM), rheumatic or autoimmune diseases, immunodeficiency diseases, and CAEV.

EBV is the most frequent antigen activator of SHLH [7]. The pathological changes in IM and CAEV differ. In contrast to B cell infection in IM, CAEV features the proliferation and infection of polyclonal, predominantly non-CD8 ${ }^{+}\left(\mathrm{CD} 4^{+} \mathrm{CD} 8^{-}\right.$and $\left.\mathrm{CD} 4^{+} \mathrm{CD} 8^{+}\right) \mathrm{T}$ cells, and $\mathrm{CD}^{+} 6^{+}$natural killer (NK) lymphocytes [8]. In CAEV, mortality generally results from the subsequent development of $\mathrm{HLH}$ and/or T/NK lymphoproliferative neoplasm [9]. The prognosis is poor once CAEV develops into HLH [9]. Chronic granulomatous disease is an inherited disorder of phagocyte nicotinamide adenine
Table 3 Results of multivariate analysis of prognostic factors of malignancy-associated hemophagocytic lymphohistiocytosis $(\mathrm{HLH})$

\begin{tabular}{llll}
\hline Variable & HR & $95 \% \mathrm{Cl}$ & $p$ value \\
\hline Group & 1.893 & $0.698-5.134$ & 0.210 \\
Age & 1.069 & $0.939-1.219$ & 0.313 \\
Sex & 0.855 & $0.351-2.082$ & 0.730 \\
EBV-positive & 0.861 & $0.375-1.980$ & 0.725 \\
@Ne & 0.963 & $0.789-1.175$ & 0.708 \\
HGB $(<60$ g/L) & 0.973 & $0.950-0.997$ & 0.027 \\
Fibrinogen & 1.242 & $0.808-1.910$ & 0.322 \\
Ferritin & 1.000 & $1.000-1.000$ & 0.235 \\
LDH & 1.000 & $1.000-1.000$ & 0.714 \\
DIC & 1.745 & $0.700-4.353$ & 0.232 \\
Jaundice & 1.911 & $0.715-5.105$ & 0.197 \\
Bone marrow involvement & 0.374 & $0.151-0.928$ & 0.034 \\
TG & 0.897 & $0.725-1.110$ & 0.316 \\
PLT (<30 $\left.\times 10^{9} / L\right)$ & 1.000 & $0.992-1.007$ & 0.917 \\
Albumin $(<25$ g/L) & 0.875 & $0.783-0.976$ & 0.017 \\
ALT & 1.000 & $0.999-1.001$ & 0.615 \\
AST & 1.000 & $1.000-1.001$ & 0.491 \\
Splenomegaly & 0.641 & $0.238-1.727$ & 0.379 \\
Cholecystitis & 1.329 & $0.381-4.641$ & 0.655 \\
Pleural effusion & 0.520 & $0.189-1.431$ & 0.205 \\
Pneumonia & 1.135 & $0.521-2.476$ & 0.750 \\
\hline HR Hazad & &
\end{tabular}

HR Hazard ratio, 95\% Cl 95\% confidence interval, EBV Epstein-Barr virus, HGB Hemoglobin, $L D H$ Lactate dehydrogenase, DIC Disseminated intravascular coagulation, TG Triglycerides, PLT Platelets, ALT Alanine aminotransferase, AST Aspartate aminotransferase, @Ne Neutrophils granulocyte

dinucleotide phosphate (NADPH) oxidase, which may be associated with HLH $[10,11]$. HLH is characterized by impaired function of $\mathrm{T}$ cell-mediated inflammation, which is partly regulated by NADPH oxidase. This pathophysiological cooperation may account for the increased severity.

EBV-related HLH is an acquired, infection-related HLH that typically represents a fulminant presentation of acute EBV infection of $\mathrm{CD}^{+} \mathrm{T}$ cells, and has a mortality rate of $30-50 \%$ [8]. In the present study, $30.4 \%$ of the children with non-malignancy-associated HLH were EBV-positive; eight patients (36.4\%) with malignancyassociated HLH were positive for EBV infection. Ahn et al. [12] suggested that patients with high EBV DNA viral load have poor prognosis. In the present cohort, a 12-year-old girl with $\gamma \delta \mathrm{T}$ cell lymphoma relapsed and developed hemophagocytic syndrome after receiving chemotherapy for 6 weeks; she died of severe EBV infection. Strenger et al. [13] found that malignancy-induced HLH concurrent with EBV infection might be a possible trigger in immunocompromised patients. 
In children, HLH may be associated with SLE, a systemic autoimmune disorder involving multiple visceral organs. In HLH due to SLE, corticosteroids and immunosuppressive agents, including cyclosporine, cyclophosphamide, intravenous immunoglobulin, and etoposide, have been used with variable success [14].

In the present study, patients with non-malignancyassociated HLH had significantly higher $\operatorname{HGB}(p=$ $0.004)$, ALT $(p=0.002)$, and AST $(p=0.001)$ levels than the patients with malignancy-associated HLH. The cause of low HGB in malignancy-associated HLH may be associated with the inhibition of hematopoiesis by malignance and chemotherapy. However, the cause of high ALT and AST levels in non-malignancy-associated HLH is unclear. Damage to liver function is characterized by severe inflammation and immune-mediated organ damage. Inflammatory cell proliferation and infiltration into organs and tissues and uncontrolled hypercytokinemia in non-malignancy-associated HLH may be more obvious than that in malignancy-associated HLH [15].

The difference in survival time was not statistically significant between the two groups $(p=0.055)$. However, previous studies have confirmed that patients with malignancy have worse survival than those without malignancy [16-18]. Celkan et al. [19] reported 54\% overall survival in 13 children and adolescents with malignancy-associated HLH. The 13 children included five patients with leukemia; eight patients with rhabdomyosarcoma, neuroblastoma, or lymphoma; and one patient with Langerhans cell histiocytosis. Another study reported that the 2-year survival rate of 25 children with malignancy-associated HLH was $40.9 \%$, and survival was $56 \%$ following the acute phase of HLH; a 5-year survival rate of $36 \%$ has also been reported [20]. We did not detect significant differences in outcome between malignancy-associated HLH and non-malignancy-associated HLH. Our results show that the low survival rate in the latter group might be due to CAEV, immunodeficiency diseases, and autoimmune diseases, as the prognosis of the abovementioned underlying diseases was poor.

The factors that affect survival are not well known, and there are currently no standard outcome predictors for SHLH. Recent data have shown that ferritin reduction is a prognostic variable for mortality in children with HLH [21]. Following univariate analysis, Park et al. [22] found that serum Fib $\geq 166 \mathrm{mg} / \mathrm{dL}$ at the initial visit was significantly associated with survival time. Low histiocyte proportion in the bone marrow and early initiation of treatment are generally correlated with favorable outcome. However, we did not find any relationship between the decline in serum ferritin, Fib level, and survival. Univariate analysis demonstrated that DIC score $>5$ at diagnosis $(p=$ $0.001)$ and albumin $<25 \mathrm{~g} / \mathrm{L}(p=0.000), \mathrm{HGB}<60 \mathrm{~g} / \mathrm{L}$ $(p=0.001)$, and PLT $<30 \times 10^{9} / \mathrm{L}(p=0.042)$ were negative prognostic factors for patients with malignancy-associated
HLH. The multivariate analysis showed that $\mathrm{HGB}<60 \mathrm{~g} / \mathrm{L}$ $(p=0.027)$, albumin $<25 \mathrm{~g} / \mathrm{L}(p=0.017)$, and bone marrow hemophagocytosis $(p=0.034)$ were negative prognostic factors for both groups. A previous comprehensive study involving 52 Turkish children with HLH suggested that high DIC score $(\geq 5)$ and age $<2$ years at diagnosis are important risk factors that can increase the mortality risk by twofold [23]. We also found that high DIC score $(\geq 5)$ and low albumin, HGB, and PLT levels predict poor progress.

Most cases of non-malignancy-associated HLH should be treated aggressively with standard HLH protocols. In particular, the prognosis for such cases has improved dramatically with chemotherapy and immune-modifying agents such as corticosteroids, intravenous immunoglobulins, cyclosporin A, and etoposide.

The treatment of malignancy-associated HLH has not been prospectively studied. In the present study, the malignancy-associated cohort received malignancy-directed treatments, HLH-directed treatments, or a combined approach to overcome HLH. However, we could not determine which approach was superior. In a murine model of familial HLH type 2, mice that received etoposide, cyclophosphamide, or methotrexate survived [24]. Regimens involving the three agents can possibly treat malignancyassociated HLH. Moreover, clinical experience is greatest for etoposide [25]. In malignancy-associated HLH, 13 patients (59.1\%) received etoposide as initial therapy for HLH, and six children are alive; the survival rate was $46.2 \%$. Therefore, we found that etoposide is effective.

Stem cell transplantation might be considered consolidation in malignancy-associated HLH. The complete remission rate of malignancy-associated HLH was $90 \%$. Therefore, stem cell transplantation is an effective therapy.

\section{Conclusions}

We analyzed a single center's experience with malignancyassociated HLH and non-malignancy-associated HLH in children. The etiology of malignancy-associated SHLH is unclear. New research has demonstrated that an underlying polygenic inheritance defect should be suspected in acquired HLH [4]. Prospective studies with a randomized controlled design and involving large cohorts of children are warranted to evaluate the exact incidence, clinical features, and appropriate treatment protocols of this association. Mutation analysis, effective diagnostic criteria, and new targeted treatments for HLH for improving the survival rate of patients with malignancy-associated HLH are necessary.

\section{Abbreviations}

ALL: Acute lymphoblastic leukemia; ALT: Alanine aminotransferase: AML: Acute myeloblastic leukemia; ANC: Absolute neutrophil count; AST: Aspartate aminotransferase; CAEV: Chronic active EBV infection; DIC: Disseminated intravascular coagulation; Fib: Fibrinogen; HD: Hodgkin 
lymphoma; HLH: Hemophagocytic lymphohistiocytosis; HSCT: Hematopoietic stem cell transplantation; IM: Infectious mononucleosis; NADPH: Nicotinamide adenine dinucleotide phosphate; NK: Natural killer; PLT: Platelet; SHLH: secondary HLH; SLE: systemic lupus erythematosus

\section{Acknowledgements}

We thank Professor Yili WU for providing the medical statistics of the data.

\section{Authors' contributions}

All authors contributed to the conception and design, and gave final approval of the version to be published. In detail, HP drafted the manuscript. YMH and LRS drafted the manuscript.

\section{Funding}

This study is supported by the Affiliated University of Qingdao University. Editorial support was funded by Li-rong Sun.

\section{Availability of data and materials}

Data are available from the authors upon reasonable request.

\section{Ethics approval and consent to participate}

A copy of the written consent form is available for review by the editor of this journal. The study has been performed with the approval of the Ethics Committee of the Affiliated University of Qingdao University(no: 20161013). The protocol has been designed and the study will be conducted in line with the principles of the Declaration of Helsinki (1964).

\section{Consent for publication}

Not applicable.

\section{Competing interests}

The authors declare that they have no competing interests.

\section{Author details}

'Department of Paediatric Hematology, Affiliated Hospital of Qingdao University, 16 Jiangsu Road, Qingdao 266003, Shandong, China. 'Department of Paediatrics, Women and Children's Health Care Hospital of Linyi, 187 Qiyang Road, Linyi 276000, Shandong, China.

Received: 30 March 2018 Accepted: 30 August 2019

Published online: 29 November 2019

\section{References}

1. Pachlopnik SJ, Côte M, Ménager MM, Burgess A, Nehme N, Ménasché G, et al. Inherited defects in lymphocyte cytotoxic activity. Immunol Rev. 2010;235:10-23.

2. Janka GE. Familial and acquired hemophagocytic lymphohistiocytosis. Annu Rev Med. 2012;63(12):233-46.

3. Johnson B, Giri S, Nunnery SE, Wiedower E, Jamy O, Yaghmour G, et al. Comorbidities drive outcomes for both malignancy-associated and nonmalignancy-associated Hemophagocytic syndrome. Clin Lymphoma Myeloma Leuk. 2016;16(4):230-6.

4. Henter Jl, Horne A, Aricó M, Egeler RM, Filipovich AH, Imashuku S, et al. HLH-2004: diagnostic and therapeutic guidelines for hemophagocytic lymphohistiocytosis. Pediatr Blood Cancer. 2007:48(2):124-31.

5. Levi M, Toh CH, Thachil J, et al. Guidelines for the diagnosis and management of disseminated intravascular coagulation. British Committee for Standards in Haematology. Br J Haematol. 2009;145:24-33.

6. Delavigne K, Bérard E, Bertoli S, Corre J, Duchayne E, Demur C, et al. Hemophagocytic syndrome in patients with acute myeloid leukemia undergoing intensive chemotherapy. Haematologica. 2014;99(3):474-80.

7. Ménard F, Besson C, Rincé P, Lambotte O, Lazure T, Canioni D, et al. Hodgkin lymphoma-associated hemophagocytic syndrome: a disorder strongly correlated with Epstein-Barr virus. Clin Infect Dis. 2008;47(4):531-4.

8. Kasahara Y, Yachie A, Takei K, Kanegane C, Okada K, Ohta K, et al. Differential cellular targets of Epstein-Barr virus (EBV) infection between acute EBV-associated hemophagocytic lymphohistiocytosis and chronic active EBV infection. Blood. 2001;98(6):1882-8.

9. Kimura H, Hoshino Y, Kanegane H, Tsuge I, Okamura T, Kawa K, et al. Clinical and virologic characteristics of chronic active Epstein-Barr virus infection. Blood. 2001;98(2):280-6.
10. Segal BH, Veys P, Malech H, Cowan MJ. Chronic granulomatous disease: lessons from a rare disorder. Bio Blood Marrow Transplant. 2011;17(1):S123-31.

11. Rieber N, Hector A, Kuijpers T, Roos D, Hartl D. Current concepts of hyperinflammation in chronic granulomatous disease. Clin Dev Immunol. 2012;2012:252460

12. Ahn JS, Rew SY, Shin MG, Kim HR, Yang DH, Cho D, et al. Clinical significance of clonality and Epstein-Barr virus infection in adult patients with hemophagocytic lymphohistiocytosis. Am J Hematol. 2010;85:719-22.

13. Strenger V, Merth G, Lackner H, et al. Malignancy and chemotherapy induced haemophagocytic lymphohistiocytosis in children and adolescents-a single centre experience of 20 years. Ann Hematol. 2018. https://doi.org/10.1007/s00277-018-3254-4.

14. Strout MP, Seropian S, Berliner N. Alemtuzumab as a bridge to allogeneic SCT in atypical hemophagocytic lymphohistiocytosis. Nat Rev Clin Oncol. 2010;7(7):415-20.

15. Gupta S, Weitzman S. Primary and secondary hemophagocytic lymphohistiocytosis: clinical features, pathogenesis and therapy. Expert Rev Clin Immunol. 2010;6(1):137-54

16. Parikh SA, Kapoor P, Letendre L, Kumar S, Wolanskyj AP. Prognostic factors and outcomes of adults with hemophagocytic lymphohistiocytosis. Mayo Clin Proc. 2014;89(4):484-92.

17. Lim SH, Park S, Jang JH, Kim K, Kim HJ, Kim SH, et al. Clinical significance of bone marrow hemophagocytosis in adult patients with malignancy and non-malignancy-induced hemophagocytic lymphohistiocytosis. Ann Hematol. 2016;95(2):325-35.

18. Ishii E, Ohga S, Imashuku S, Yasukawa M, Tsuda H, Miura I, et al. Nationwide survey of hemophagocytic lymphohistiocytosis in Japan. Int J Hematol. 2007:86(1):58-65.

19. Celkan T, Berrak S, Kazanci E, Ozyürek E, Unal S, Uçar C, et al. Malignancyassociated hemophagocytic lymphohistiocytosis in pediatric cases: a multicenter study from Turkey. Turk J Pediatr. 2009;51(3):207-13.

20. Veerakul G, Sanpakit K, Tanphaichitr VS, Mahasandana C, Jirarattanasopa N. Secondary hemophagocytic lymphohistiocytosis in children: an analysis of etiology and outcome. J Med Assoc Thail. 2002;85(Suppl 2):S530-41.

21. Lin TF, Ferlic-Stark LL, Allen CE, Kozinetz CA, McClain KL. Rate of decline of ferritin in patients with hemophagocytic lymphohistiocytosis as a prognostic variable for mortality. Pediatr Blood Cancer. 2011:56(1):154-5.

22. Park HS, Kim DY, Lee JH, Lee JH, Kim SD, Park YH, et al. Clinical features of adult patients with secondary hemophagocytic lymphohistiocytosis from causes other than lymphoma: an analysis of treatment outcome and prognostic factors. Ann Hematol. 2012;91 (6):897-904.

23. Kaya Z, Bay A, Albayrak M, Kocak U, Yenicesu I, Gursel T. Prognostic factors and long-term outcome in 52 Turkish children with Hemophagocytic Lymphohistiocytosis. Pediatr Crit Care Med. 2015;16(6):e165-73.

24. Johnson TS, Terrell CE, Millen SH, Katz JD, Hildeman DA, Jordan MB. Etoposide selectively ablates activated $\mathrm{T}$ cells to control the immunoregulatory disorder hemophagocytic lymphohistiocytosis. J Immunol. 2014;192(1):84-91.

25. Arca M, F L, Galicier L, Rivière S, Marzac C, Aumont C, et al. Prognostic factors of early death in a cohort of 162 adult haemophagocytic syndrome: impact of triggering disease and early treatment with etoposide. $\mathrm{Br} J$ Haematol. 2015;168(1):63-8.

\section{Publisher's Note}

Springer Nature remains neutral with regard to jurisdictional claims in published maps and institutional affiliations.

Ready to submit your research? Choose BMC and benefit from

- fast, convenient online submission

- thorough peer review by experienced researchers in your field

- rapid publication on acceptance

- support for research data, including large and complex data types

- gold Open Access which fosters wider collaboration and increased citations

- maximum visibility for your research: over $100 \mathrm{M}$ website views per year

At BMC, research is always in progress.

Learn more biomedcentral.com/submission 